\title{
Improving the Swallowing in Total Glossectomy With Laryngeal Preservation
}

Giovanni Cristalli ${ }^{1,2, *}$, Pasquale Di Maio ${ }^{3}$, Giulio Vallati ${ }^{4}$, Ronel D'Amico ${ }^{4}$, Antonello Vidiri ${ }^{4}$, Giuseppe Mercante ${ }^{5,6}$, Fabio Ferreli ${ }^{6}$, Francesca Boscolo Nata $^{1}$, Fabiola Giudici ${ }^{7}$, Raul Pellini ${ }^{2}$, Oreste Iocca ${ }^{5,6}$, Giuseppe Spriano ${ }^{5,6}$

${ }^{1}$ ENT Department, United Hospitals Padua South Mother Teresa of Calcutta, Monselice, Italy

${ }^{2}$ Department of Otolaryngology Head and Neck Surgery, Regina Elena National Cancer Institute, Roma, Italy

${ }^{3}$ Department of Otolaryngology Head and Neck Surgery, Civil Hospital, Sanremo, Italy

${ }^{4}$ Department of Radiology, Regina Elena National Cancer Institute, Roma, Italy

${ }^{5}$ Humanitas Clinical and Research Center IRCCS, Rozzano, Italy

${ }^{6}$ Department of Biomedical Sciences, Humanitas University, Milan, Italy

${ }^{7}$ Unit of Biostatistics, Epidemiology and Public Health, Department of Cardiac, Thoracic, Vascular Sciences and Public Health, University of Padua, Padua, Italy

*Corresponding author: Giovanni Cristalli, Otolaryngology Department, ENT Department, United Hospitals Padua South Mother Teresa of Calcutta, Via Albere, 30, 35043 Monselice, PD, Italy. Tel: +393282212103; Fax:

DOI: $10.30699 / \mathrm{mci} .5 .2 .444-1$ +390429/715497; E-mail:giovanni.cristalli@gmail.com

Submitted: 8 August 2020

Revised: 9 November 2020

Accepted: 20 December 2020

e-Published: 26 January 2021

\section{Keywords:}

Tongue Neoplasms

Reconstructive Surgical Procedures

Surgical Flaps

Deglutition

Fluoroscopy
Introduction: This study aims to evaluate the parameters that might have an impact on swallowing performance after a total glossectomy with laryngeal preservation (TGLP). Methods: Among 39 patients who underwent surgery with curative intent for squamous cell carcinoma of the tongue, our retrospective analysis focused on 18 patients treated by TGLP and flap reconstruction. The flap was positioned using three points of suspension: mandible (anteriorly), remaining suspensor muscles (cranially), and hyoid bone (inferiorly). Videofluoroscopic swallowing studies were performed after surgery, and the movements of the hyoid bone on the horizontal and vertical plane were measured on a frame-by-frame basis, and the velopharyngeal contact was recorded. Swallowing was studied at consecutive time-intervals using the Gugging Swallowing Screen (GUSS), and patients were categorized into three groups according to their swallowing ability (good, intermediate, and bad). The relationship between categorical and continuous variables and the swallowing ability were investigated using the chi-squared or Fischer exact test and Mann-Whitney test or t-student test respectively.

Results: Swallowing ability at 6-8 months was good in 13 patients and intermediate or bad in five patients. Swallowing improved in 1 and 3 patients at 12 and 18 months, respectively. The hyoid bone movement in the $\mathrm{y}$-axis and extension of surgery to the tonsil were statistically associated with swallowing $(\mathrm{P}=0.002$ and $\mathrm{P}=0.04$, respectively). Velopharyngeal contact was obtained in the entire cohort.

Conclusions: Flap suspension using three points of attachment, could allow the restoration of an active hyoid movement and the velopharyngeal closure, thereby achieving valid swallowing. 


\section{INTRODUCTION}

Total glossectomy (TG) is a devastating surgical treatment for locally advanced tongue cancer, a disease with limited therapeutic options. Although the preservation of valid swallowing and phonation is often unpredictable, its oncological results are acceptable. Due to the widespread use of pedicle and free flaps since the 1980s, TG with laryngeal preservation (TGLP) has gradually increased. According to the literature, the dependence on tracheostomy and gastrostomy after TGLP ranges between $27 \%$ and $76 \%$ [1-4]. To improve swallowing after TGLP, variations of the surgical technique have been proposed, focusing mainly on the type of reconstruction (free, pedicle, innervated/ re-innervated flaps, or the role of the bulk of the flap) or on the static suspension of the hyoid bone. Due to limited series samples and poor stratification of cases, definitive conclusions cannot be drawn [5]. Hyoid movement and velopharyngeal closure, which are influenced by the flap positioning technique, should be considered during surgical reconstruction. Here, we aim to demonstrate the impact of hyoid position and movements on functional outcome after TGLP. Specifically, some technical refinements on flap placement are presented and functionally analyzed.

\section{METHODS}

This retrospective study was conducted in accordance with the Declaration of Helsinki (1964) and with the approval of the local ethics committee (RS1167/18). We retrospectively reviewed clinical and pathological data of patients undergoing surgery with curative intent for squamous cell carcinoma of the tongue from August 2012 to November 2017 at the division of otolaryngology, head and neck surgery, I.F.O., Rome, Italy. Patients signed the written informed consent for the use of their data. The patients were selected according to the following inclusion criteria: TGLP combined with ipsilateral or bilateral neck dissection according to the National Comprehensive Cancer Network (NCCN) guidelines [6], and patients undergoing post-operative videoendoscopic and videofluoroscopic study. Total glossectomy was defined as complete removal of the tongue down to the vallecula on both sides [7]. The exclusion criteria were uncooperative patients, severe neurological diseases, and total glossectomy associated with mandibular resection. The superior laryngeal nerve was identified and preserved in all patients. The flaps used for reconstruction are listed in Table 1. Flap placement was performed by cranially suturing the flap to the following muscles: middle constrictor of the pharynx, styloglossus, stylohyoid and stylo-pharyngeal muscles (Riolan bundle), palatoglossus, palatopharyngeal, salpingoglossus, and salpingopharyngeal muscles (Figure 1) on both sides to ensure the suspension of the flap close to the soft palate (Figure 2). Anteriorly, the flap was firmly sutured to the mandible. The inferior edge of the flap was firmly sutured using high diameter absorbable stitches surrounding the body of the hyoid bone and the mucosa of the vallecula.

\begin{tabular}{|c|c|}
\hline \multicolumn{2}{|c|}{ Table 1: Patients and Tumor Characteristics (pTNM $7^{\text {th }}$ ed.) } \\
\hline & $\begin{array}{l}\text { All Cohort } \\
(n=18)\end{array}$ \\
\hline Age, mean \pm SD & $60.2 \pm 11.0$ \\
\hline \multicolumn{2}{|l|}{ Gender, No.(\%) } \\
\hline Male & $13(72.2)$ \\
\hline Female & $5(27.8)$ \\
\hline \multicolumn{2}{|l|}{ ASA Score, No.(\%) } \\
\hline 2 & $10(55.6)$ \\
\hline 3 & $8(44.4)$ \\
\hline \multicolumn{2}{|l|}{ Smoking, No.(\%) } \\
\hline Yes & $13(72.2)$ \\
\hline No & $5(27.8)$ \\
\hline \multicolumn{2}{|l|}{ Alcohol, No.(\%) } \\
\hline Yes & $6(33.3)$ \\
\hline No & $12(66.7)$ \\
\hline $\begin{array}{l}\text { Hyoid Bone Movement X-Axis, mm, median } \\
\text { (min-max) }\end{array}$ & $\begin{array}{r}13.0(4.0- \\
36.0)\end{array}$ \\
\hline $\begin{array}{l}\text { Hyoid Bone Movement Y-Axis, mm, median } \\
\text { (min-max) }\end{array}$ & $\begin{array}{r}10.5(2.0- \\
16.0)\end{array}$ \\
\hline \multicolumn{2}{|l|}{ Epiglottis Infiltration, No.(\%) } \\
\hline Yes & $1(5.6)$ \\
\hline No & $17(94.4)$ \\
\hline \multicolumn{2}{|l|}{ Epiglottis Preservation, No.(\%) } \\
\hline Yes & $17(94.4)$ \\
\hline No & $1(5.6)$ \\
\hline \multicolumn{2}{|l|}{ Surgery Extended to Tonsil, No.(\%) } \\
\hline Yes & $4(22.2)$ \\
\hline No & $14(77.8)$ \\
\hline \multicolumn{2}{|l|}{ Surgical Approach, No.(\%) } \\
\hline Pull Through & $16(88.9)$ \\
\hline Transmandibular & $2(11.1)$ \\
\hline
\end{tabular}




\begin{tabular}{|c|c|}
\hline \multicolumn{2}{|c|}{ Ipsilateral Neck Dissection, No.(\%) } \\
\hline Radical & $1(5.6)$ \\
\hline Modified Radical & $11(61.1)$ \\
\hline Selective 1-4 & $3(16.7)$ \\
\hline Selective 1-3 & $3(16.7)$ \\
\hline \multicolumn{2}{|c|}{ Controlateral Neck Dissection, No.(\%) } \\
\hline No & $4(22.2)$ \\
\hline Modified Radical & $3(16.7)$ \\
\hline Selective 1-4 & $2(11.1)$ \\
\hline Selective 1-3 & $9(50.0)$ \\
\hline \multicolumn{2}{|c|}{ Reconstructive Flap, No.(\%) } \\
\hline Antero Lateral Tight & $1(5.6)$ \\
\hline Pectoralis & $8(44.4)$ \\
\hline Radial Forearm & $6(33.3)$ \\
\hline Rectus Abdominis & $1(5.6)$ \\
\hline Vastus Lateralis & $2(11.1)$ \\
\hline \multicolumn{2}{|l|}{ pT, No.(\%) } \\
\hline pT2 & $7(38.9)$ \\
\hline pT3 & $4(22.2)$ \\
\hline pT4a & $7(38.9)$ \\
\hline \multicolumn{2}{|l|}{ pN, No.(\%) } \\
\hline No & $9(50.0)$ \\
\hline N1 & $1(5.6)$ \\
\hline N2b & $4(22.2)$ \\
\hline N2c & $4(22.2)$ \\
\hline \multicolumn{2}{|c|}{ Preoperative Radiotherapy, No.(\%) } \\
\hline Yes & $4(22.2)$ \\
\hline No & 14(77.8) \\
\hline \multicolumn{2}{|c|}{ Preoperative Chemotherapy, No.(\%) } \\
\hline Yes & $2(11.1)$ \\
\hline No & $16(88.9)$ \\
\hline \multicolumn{2}{|c|}{ Post-Operative Radiotherapy, No.(\%) } \\
\hline Yes & 14(77.8) \\
\hline No & $4(22.2)$ \\
\hline \multicolumn{2}{|c|}{ Post-Operative Chemotherapy, No.(\%) } \\
\hline Yes & $8(44.4)$ \\
\hline No & 10(55.6) \\
\hline \multicolumn{2}{|c|}{ Velopharyngeal Closure, No.(\%) } \\
\hline Yes & $18(100.0)$ \\
\hline No & $0(0.0)$ \\
\hline \multicolumn{2}{|c|}{ Swallowing at 6-8 Months, No.(\%) } \\
\hline Good & $13(72.2)$ \\
\hline Intermediate & $3(16.7)$ \\
\hline Bad & $2(11.1)$ \\
\hline
\end{tabular}

${ }^{a}$ Abbreviation; ASA, American Society of Anesthesiologists

Endoscopic swallowing evaluation was performed with an Olympus endoscope (ENF type VQ 3.6 $\mathrm{mm}$ ) and recorded on a workstation (Olympus,
Tokyo, Japan). The patients were tested with three different consistencies: Five cc apple puree with $5 \%$ methylene blue, Five cc liquid water with 5\% methylene blue, and 1/4 biscuit (regular consistency) [10]. Swallowing was evaluated using the Gugging Swallowing Screen (GUSS) [11]. Patients were categorized into three groups of swallowing ability according to their severity code: good (slight/no dysphagia with minimal risk of aspiration, or slight dysphagia with a low risk of aspiration), intermediate (moderate dysphagia with a risk of aspiration), or bad (severe dysphagia with a high risk of aspiration). Considering that results and outcomes in surgical procedures may be affected by some background or confounder variables such as time, videoendoscopic swallowing studies were performed at consecutive time intervals (12 and 18 months) after surgery or postoperative radio(chemo) therapy.

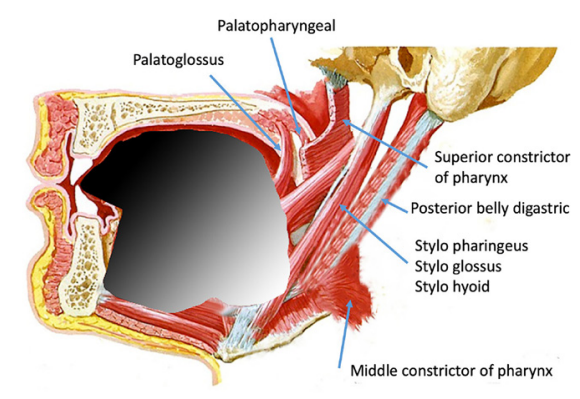

A

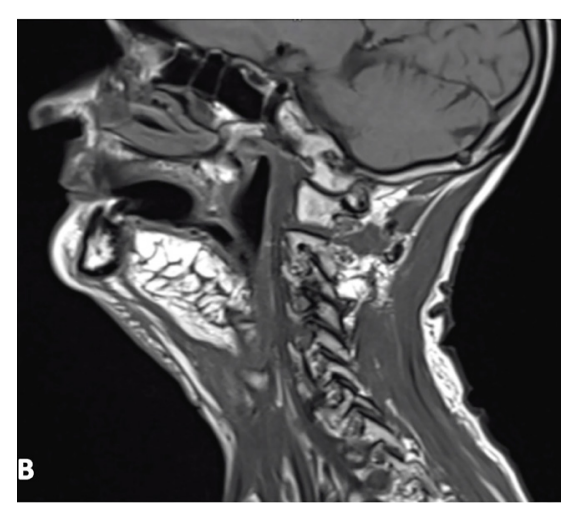

Figure 1: Effect of Total Glossectomy and Positioning of the Reconstructive Flap

A) After total glossectomy, the suprahyoid muscles are sectioned to obtain an "en bloc" resection with the tongue. The superior anchorage to the remaining parts of some of these muscles and other muscles (palatoglossus, palatopharyngeal, superior constrictor, stylopharyngeus, and styloglossus) can be used to cranially suture the flap. By this approach, hyoid bone movement on the $y$-axis and velopharyngeal closure is obtained. B) At the sagittal MRI, a more cranial position of the reconstructive flap is appreciable. 

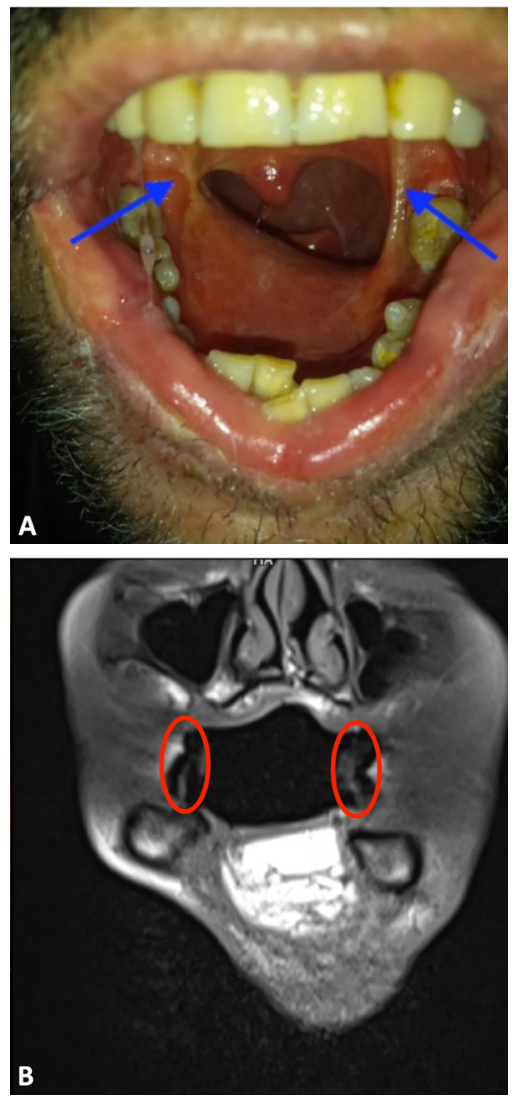

Thomas was used to identify a point in the cervical vertebrae and the direction of the long axis of the spine passing through this point [9]. Moreover, videofluoroscopy was used to verify the contact between the reconstructive flap and soft palate.

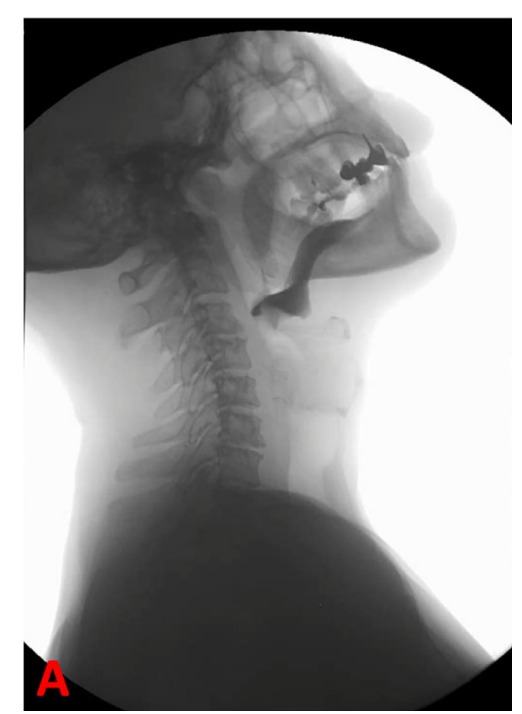

Figure 2: Appearance of the Cranial Suspension of the Flap A) Clinical appearance of the cranial suspension of the flap to the remaining suspensor muscle (blue arrows); B) Radiologic image of the cranial suspension of the flap to the remaining suspensor muscle (red circles).

All patients underwent adequate post-operative rehabilitation therapy for swallowing and speech. Videofluoroscopic and videoendoscopic swallowing studies were conducted within 6-8 months after surgery or postoperative radio(chemo) therapy. The videofluoroscopy swallowing study was performed using radiographic equipment (model Opera D4000, General Medical Merate, Seriate Bergamo, Italy), liquid bolus ( $60 \%$ water and $40 \%$ Gastrografin $($ ) , and thick bolus obtained by adding a thickening powder (AM PLUS, DMF -Dietetic

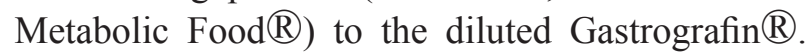
The videotapes were analyzed by a radiologist experienced in videofluoroscopic evaluation (Figure 3). Videofluoroscopy was used to evaluate hyoid bone movements according to the method proposed by Kellen [8]. The movements of the hyoid bone on the horizontal (x-axis) and vertical (y-axis) plane were measured for the whole video sequence. The $\mathrm{x}$-axis was defined as a line crossing the $\mathrm{y}$-axis at the origin of $\mathrm{C} 4$. The method described by Kumar and

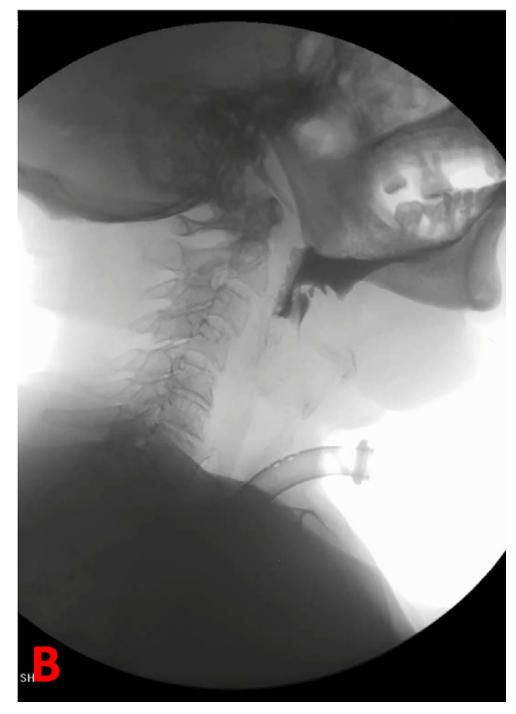

Figure 3: Videofluoroscopic Swallowing Studies A) A patient with good swallowing; B) A patient with bad swallowing

\section{Statistical Analysis}

Categorical variables were reported as percentages; continuous variables were summarized as mean \pm standard deviation or median and range as appropriate, according to the data distribution. The normality of the continuous variables was tested; using the Shapiro-Wilk test. Patients were stratified into two groups according to swallowing ability (good vs. intermediate/bad). We decided to merge intermediate and bad swallowing into a single 


\begin{tabular}{|c|c|c|c|c|c|c|c|}
\hline & & \multicolumn{3}{|c|}{12 Months Swallowinga } & \multicolumn{3}{|c|}{18 Months Swallowing ${ }^{b}$} \\
\hline & & Intermediate/Bad & Total & Good & Good & Intermediate/Bad & Total \\
\hline \multirow{3}{*}{ 6-8 Months Swallowing } & Good & 13 & 0 & 13 & 13 & 0 & 13 \\
\hline & Intermediate/Bad & 1 & 4 & 5 & 3 & 2 & 5 \\
\hline & Total & 14 & 4 & 18 & 16 & 2 & 18 \\
\hline
\end{tabular}

${ }^{a}$ One patient improved but the difference was not statistically significant $(\mathrm{P}=1)$.

${ }^{\mathrm{b}}$ Three patients improved but the difference was not statistically significant $(\mathrm{P}=0.25)$.

category because of the small sample sizes of these two subgroups. Test of symmetry - or marginal homogeneity - for nominal paired data repeated in time (the equivalent of Mc-Nemar test in the presence of low counts in the discordant cells of contingency tables) was used to compare the swallowing ability in relation to three different time points (6-8 months, 12 months and 18 months). To identify variables associated with swallowing ability, we compared categorical parameters [gender, American Society of Anesthesiologists (ASA) score, smoking and alcohol consumption, pre-and postoperative radiotherapy (RT) or chemotherapy (CT), surgical approach, epiglottis infiltration, epiglottis preservation, surgery extended to the tonsillar fossa, type of neck dissection, type of reconstructive flap, and tumor and node pathologic staging (pTNM $7^{\text {th }}$ edition)] using the chi-squared or Fischer exact test. Continuous variables (age, hyoid bone movement on the $\mathrm{x}$ - and y-axis) were analyzed using the Mann-Whitney test or t-student test. Multivariate analysis was not performed because the ratio of events per variable was too small [only five patients with intermediate/ bad swallowing (events)]. Thus, carrying out a multivariable model could affect risk estimates and precision of odds ratios, resulting in misleading findings. R software (version 3.5.0, 2019) was used for statistical analysis. $\mathrm{P}<0.05$ were considered as statistically significant.

\section{RESULTS}

From August 2012 to November 2017, a total of 39 patients with tongue cancer underwent surgery and 18 patients met the inclusion criteria to be considered in this study. Patients and tumor characteristics are presented in Table 1. According to GUSS, swallowing at 6-8 months was considered good in 13, intermediate in 3 (moderate aspiration), and bad in 2 (significant aspiration) patients. We did not observe statistically significant differences in swallowing at 12 months $(\mathrm{P}=1)$ (Table 2$)$ and 18 months postoperatively $(\mathrm{P}=0.25)$ (Table 2$)$, even if 1 and 3 patients improved their condition from bad/intermediate to good swallowing at 12 and 18 months after surgery, respectively.

At videofluoroscopy performed at 6-8 months postoperatively, the median hyoid bone movement on the $\mathrm{x}$-axis (anteroposterior) was $13 \mathrm{~mm}$ (range, 4-34 $\mathrm{mm}$ ) in patients with good swallowing and $24 \mathrm{~mm}$ (range, 4-36 mm) in patients with bad/ intermediate swallowing. The median hyoid bone movement on the y-axis (vertical movement) was $11 \mathrm{~mm}$ (range, 7-16 mm) in patients with good swallowing and $3 \mathrm{~mm}$ (range, 2-5 $\mathrm{mm}$ ) in patients with bad/intermediate swallowing. Velopharyngeal closure was obtained in the entire cohort. Hyoid bone movement in the y-axis and extension of surgery to the tonsil were statistically associated with swallowing ability $(\mathrm{P}=0.002$ and $\mathrm{P}=0.04$, respectively) (Table 3).

\section{DISCUSSION}

In TGLP, suspension and movement of the larynx during swallowing are completely modified functions due to the lack of superior muscle attachment to the hyoid bone [12]. Reconstruction aims to preserve the larynx and maintain valid swallowing, thereby avoiding serious complications such as aspiration pneumonia. Many factors can impact swallowing. Regarding reconstruction, there is non-definitive evidence that free flaps are better than pedicle flaps or that the motor or sensory innervation can lead to a better swallowing [13]. On the other hand, a consensus has been reached on the most relevant parameters that can interfere with swallowing in TGLP, including suspension of the flap, velopharyngeal closure, and a valid superior laryngeal nerve function $[14,15]$. These considerations on reconstruction have to guide the surgeon to apply a different position of the flap; using 
three points of suspension: mandible (anteriorly), remaining suspensor muscles (cranially), and hyoid bone (inferiorly) (Figure 4A).

\begin{tabular}{|c|c|c|c|}
\hline & 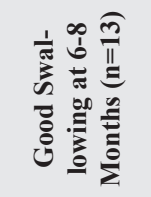 & 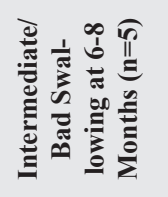 & $\begin{array}{l}\frac{\varrho}{\pi} \\
\frac{\Xi}{\pi} \\
\text { a }\end{array}$ \\
\hline Age, $\operatorname{mean} \pm$ SD & $57.8 \pm 10.1$ & $66.2 \pm 5.4$ & 0.15 \\
\hline Gender, No.(\%) & & & 0.65 \\
\hline Male & $9(69.2)$ & $4(80.0)$ & \\
\hline Female & $4(30.8)$ & $1(20.0)$ & \\
\hline ASA Score, No.(\%) & & & 0.31 \\
\hline 2 & $6(46.2)$ & $4(80.0)$ & \\
\hline 3 & $7(53.8)$ & $1(20.0)$ & \\
\hline Smoking, No.(\%) & & & 0.58 \\
\hline Yes & $10(76.9)$ & $3(60.0)$ & \\
\hline No & $3(23.1)$ & $2(40.0)$ & \\
\hline Alcohol, No.(\%) & & & 0.14 \\
\hline Yes & $3(23.1)$ & $3(60.0)$ & \\
\hline No & $10(76.9)$ & $2(40.0)$ & \\
\hline $\begin{array}{l}\text { Hyoid Bone Movement } X \text {-Axis, } \\
\text { mm, median (min-max) }\end{array}$ & $13.0(4.0-34.0)$ & $24.0(4.0-36.0)$ & 0.28 \\
\hline $\begin{array}{l}\text { Hyoid Bone Movement Y-Axis, } \\
\text { mm, median (min-max) }\end{array}$ & $11.0(7.0-16.0)$ & $3.0(2.0-5.0)$ & 0.002 \\
\hline Epiglottis Infiltration, No.(\%) & & & 0.10 \\
\hline Yes & $0(0.0)$ & $1(20.0)$ & \\
\hline No & $13(100.0)$ & $4(80.0)$ & \\
\hline Epiglottis Conservation, No.(\%) & & & 0.28 \\
\hline Yes & $13(100.0)$ & $4(80.0)$ & \\
\hline No & $0(0.0)$ & $1(20.0)$ & \\
\hline Surgery Extended to Tonsil, No.( & $(\%)$ & & 0.04 \\
\hline Yes & $1(7.7)$ & $3(60.0)$ & \\
\hline No & $12(92.3)$ & $2(40.0)$ & \\
\hline Surgical Approach, No.(\%) & & & 0.99 \\
\hline Pull Through & $11(84.6)$ & $5(100.0)$ & \\
\hline Transmandibular & $2(15.4)$ & $0(0.0)$ & \\
\hline Ipsilateral Neck Dissection, No.(\% & $\%)$ & & 0.19 \\
\hline Radical & $1(7.7)$ & $0(0.0)$ & \\
\hline Modified radical & $6(46.2)$ & $5(100.0)$ & \\
\hline Selective 1-4 & $3(23.1)$ & $0(0.0)$ & \\
\hline Selective 1-3 & $3(23.1)$ & $0(0.0)$ & \\
\hline Controlateral Neck Dissection, $\mathrm{N}$ & No. $(\%)$ & & 0.35 \\
\hline No & $4(30.8)$ & $0(0.0)$ & \\
\hline Modified radical & $2(15.4)$ & $1(20.0)$ & \\
\hline Selective 1-4 & $2(15.4)$ & $0(0.0)$ & \\
\hline Selective 1-3 & $5(38.5)$ & $4(80.0)$ & \\
\hline constructive Flap, No. & & & 0.5 \\
\hline
\end{tabular}

\begin{tabular}{|c|c|c|c|}
\hline Antero lateral tight & $1(7.7)$ & $0(0.0)$ & \\
\hline Pectoralis & $5(38.5)$ & $3(60.0)$ & \\
\hline Radial forearm & $5(38.5)$ & $1(2.0)$ & \\
\hline Rectus abdominis & $0(0.0)$ & $1(20.0)$ & \\
\hline Vastus lateralis & $2(15.4)$ & $0(0.0)$ & \\
\hline pT, No.(\%) & & & 0.13 \\
\hline pT2 & $7(53.9)$ & $0(0.0)$ & \\
\hline pT3 & $2(22.2)$ & $2(40.0)$ & \\
\hline pT4a & $4(30.8)$ & $3(60.0)$ & \\
\hline pN, No.(\%) & & & 0.12 \\
\hline No & $8(61.5)$ & $1(20.0)$ & \\
\hline N1 & $1(7.7)$ & $0(0.0)$ & \\
\hline $\mathbf{N} 2 b$ & $1(7.7)$ & $3(60.0)$ & \\
\hline $\mathrm{N} 2 \mathrm{c}$ & $3(23.1)$ & $1(20.0)$ & \\
\hline \multicolumn{2}{|c|}{ Preoperative Radiotherapy, No.(\%) } & & 0.28 \\
\hline Yes & $4(30.8)$ & $0(0.0)$ & \\
\hline No & $9(69.2)$ & $5(100.0)$ & \\
\hline \multicolumn{2}{|c|}{ Preoperative Chemotherapy, No.(\%) } & & 0.99 \\
\hline Yes & $2(15.4)$ & $0(0.0)$ & \\
\hline No & $11(84.6)$ & $5(100.0)$ & \\
\hline \multicolumn{2}{|c|}{ Post-Operative Radiotherapy, No.(\%) } & & 0.28 \\
\hline Yes & $9(69.2)$ & $5(100.0)$ & \\
\hline No & $4(30.8)$ & $0(0.0)$ & \\
\hline \multicolumn{2}{|c|}{ Post-Operative Chemotherapy, No.(\%) } & & 0.61 \\
\hline Yes & $5(38.5)$ & $3(60.0)$ & \\
\hline No & $8(61.5)$ & $2(40.0)$ & \\
\hline
\end{tabular}

a Abbreviation: ASA, American Society of Anesthesiologists

By attaching the flap to the remaining suspensor muscles, a higher position of the flap, a valid velopharyngeal contact, and a partially restored active movement towards the y-axis (up and down) during swallowing will be obtained. Even if the muscles that are attached to the superior surface of the hyoid bone (hyoglossus, digastric, stylohyoid, geniohyoid, mylohyoid) are sectioned to obtain an "en bloc" resection with the tongue, the superior anchorage to the remaining parts of this group of muscles can be used to reproduce the movement of the flap and hyoid bone during the reconstruction. Similarly, the middle pharyngeal constrictor, the palatoglossus, and palatopharyngeal muscles are supposed to be applied. The inferior edge of the flap has to be firmly sutured using absorbable high diameter stitches surrounding the body of the hyoid bone and the mucosa of the 
vallecula to avoid further restriction in the movement of the epiglottis. The action of the muscles attached to the inferior border of the hyoid bone (thyrohyoid/ sternohyoid/omohyoid) remains essentially unchanged, except for the omohyoid muscle that is usually sectioned during the neck dissection. Commonly used techniques advocate how laryngeal suspension can be reached using non-absorbable stitches between the thyroid cartilage or hyoid bone and the mandible. This method determines a static relationship between the larynx complex and flap that may minimally improve swallowing $[15,16]$. Moreover, the flap is positioned like a "slide" between the oral cavity and larynx (Figure 4B).
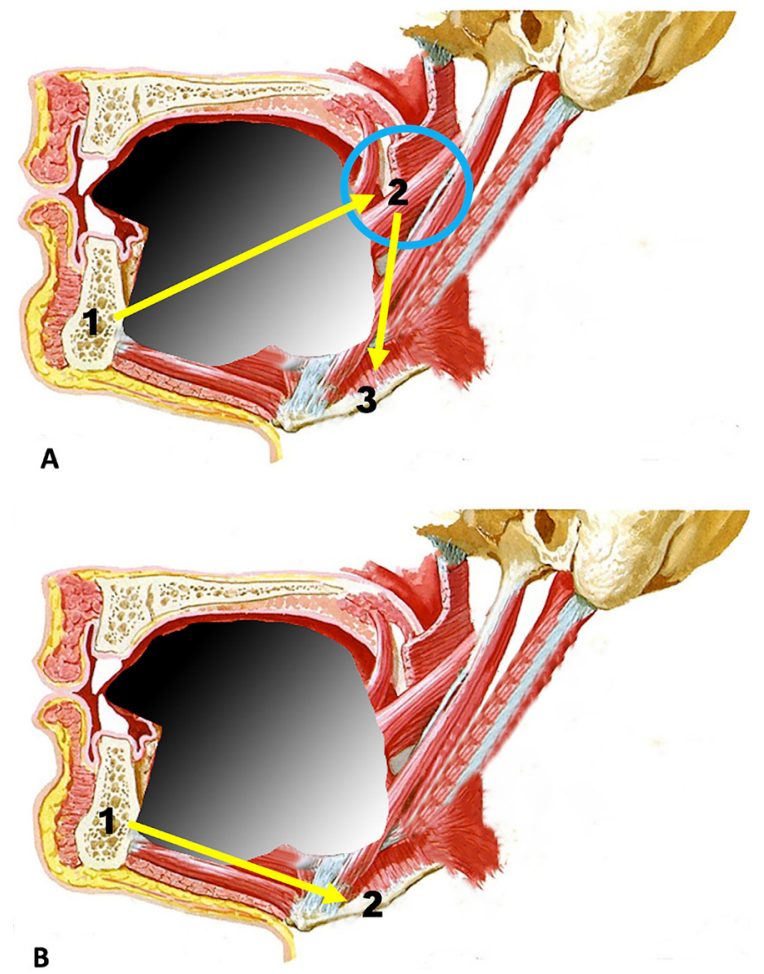

Figure 4: Different Options for Reconstructive Flap Positioning A) The reconstructive flap is positioned; using three points of suspension: 1. mandible (anteriorly), 2. remaining suspensor muscles (cranially), and 3. hyoid bone (inferiorly). By attaching it to remaining suspensor muscles, a higher position of the flap, a valid velopharyngeal contact, and a partially restoring of an active movement towards the $y$-axis (up and down) during swallowing are obtained; B) The reconstructive flap is positioned using two points of suspension: mandible (anteriorly), and hyoid bone (inferiorly). This method determines a static relationship between the larynx complex and the flap. Moreover, the flap is positioned like a "slide" between the oral cavity and larynx

In our cohort study, good swallowing at 6-8 months was obtained in $72.2 \%$ of patients $(13 / 18)$, which is in line with the best previously reported investigations
$[7,17]$. The flap positioning using three suspension points after TGLP, allowed for active movement of the hyoid bone in a vertical plane, with a statistically significant impact on swallowing $(\mathrm{P}=0.002)$. We observed an improvement in swallowing in 1 patient at 12 months, and in 3 patients at 18 months: this result, even if not statistically significant, could indicate that longer follow-ups should be performed to verify the real number of patients that could return to a good swallowing ability. After TG, the contact between the neotongue and soft palate is essential to trigger the swallowing reflex. Traditionally, this contact has been assigned to a bulky reconstructive flap [16], while the latter could impair swallowing and breathing. Conversely, the active suspension of the flap allows that contact because the flap is placed in an upper position and sutured to a muscular system that can further move it closer to the soft palate during swallowing [18]. In our cohort study, velopharyngeal closure was obtained in all cases by the fixation/placement of the flap. Weber et al., reported the results for 27 patients with TGLP. Accordingly, 14 individuals underwent laryngeal suspension with stitches between the hyoid bone and mandible, and 18 cases underwent palatal prosthesis augmentation [19]. It is reasonable to believe that the palatal augmentation allows the contact between the reconstructive flap and the soft palate, justifying the good swallowing results reported by the author. However, this method of laryngeal suspension is static as compared to the one we have proposed. The glottis closure remains active by preserving the superior laryngeal nerve [16]. This reflex protects the upper airways by closing the laryngeal vestibule and retracting the epiglottis posteriorly through the reflex nervous axis. It is important to underline that surgery extended to the lateral oropharyngeal wall in our series was associated with a poor functional outcome ( $\mathrm{P}=0.04)$. This result could be related to the impairment of the pharyngeal phase of swallowing [18]. In conclusion, laryngeal preservation after total glossectomy allows functional speech but must be balanced with the risk of aspiration. To reduce the aspiration risk, the surgeon should preoperatively evaluate the possibility to restore an active hyoid movement and the velopharyngeal closure and to maintain superior laryngeal nerve reflex to achieve valid swallowing. Flap suspension using three points of attachment tries to meet these 
needs. Surely, total glossectomy requires a complete swallowing rehabilitation with a motivated patient and close cooperation between the surgeon and the speech/swallowing therapist. Even if randomized studies are not available, we suggest avoiding larynx preservation in cases where surgery could not ensure a dynamic suspension of the reconstructive flap.

\section{ACKNOWLEDGMENTS}

The authors thank the speech therapist Dr. Alessandra Masiello and the staff of the Department of Radiology of Regina Elena National Cancer Institute.

\section{CONFLICT OF INTEREST}

Authors declare they have not competing interests.

\section{ETHICS APPROVAL}

This study was approved by the National Cancer Institute of Rome "Regina Elena" ethics committee (RS1167/18).

\section{REFERENCES}

1. Effron MZ, Johnson JT, Myers EN, Curtin H, Beery Q, Sigler B. Advanced carcinoma of the tongue. Management by total glossectomy without laryngectomy. Arch Otolaryngol. 1981;107(11):694-7. DOI: 10.1001/archotol.1981.00790470042010 PMID: 7295164.

2. Brusati R, Collini M, Bozzetti A. Total glossectomy without laryngectomy. J Maxillofac Surg. 1986;14(1):57-63. DOI: 10.1016/s0301-0503(86)80260-0 PMID: 3456415.

3. Gehanno P, Guedon C, Barry B, Depondt J, Kebaili C. Advanced carcinoma of the tongue: total glossectomy without total laryngectomy. Review of 80 cases. Laryngoscope. 1992;102(12 Pt 1):1369-71. DOI: 10.1288/00005537199212000-00011 PMID: 1453844.

4. Lin DT, Yarlagadda BB, Sethi RK, Feng AL, Shnayder Y, Ledgerwood LG, et al. Long-term Functional Outcomes of Total Glossectomy With or Without Total Laryngectomy. JAMA Otolaryngol Head Neck Surg. 2015;141(9):797803. DOI: 10.1001/jamaoto.2015.1463 PMID: 26291031.

5. Lam L, Samman N. Speech and swallowing following tongue cancer surgery and free flap reconstruction--a systematic review. Oral Oncol. 2013;49(6):507-24. DOI: 10.1016/j.oraloncology.2013.03.001 PMID: 23566773.

6. National Comprehensive Cancer Network. NCCN Clinical Practice Guidelines in Oncology (NCCN Guidelines $\left.{ }^{\circledR}\right)$. Head and Neck Cancers. Version 1.2021. Pennsylvania, USA: National Comprehensive Cancer Network (NCCN); 2021 [updated 2020 Nov 9; cited 2021 Jan 15]. Available from: https://www.nccn.org/professionals/physician_gls/ pdf/head-and-neck.pdf.

7. Keski-Santti H, Back L, Lassus P, Koivunen P, Kinnunen I, Blomster H, et al. Total or subtotal glossectomy with la- ryngeal preservation: a national study of 29 patients. Eur Arch Otorhinolaryngol. 2018;275(1):191-7. DOI: 10.1007/ s00405-017-4789-z PMID: 29119320.

8. Kellen PM, Becker DL, Reinhardt JM, Van Daele DJ. Computer-assisted assessment of hyoid bone motion from videofluoroscopic swallow studies. Dysphagia. 2010;25(4):298-306. DOI: 10.1007/s00455-009-9261-9 PMID: 19856024.

9. Kumar VP, Thomas T. Automatic estimation of orientation and position of spine in digitized X-rays using mathematical morphology. J Digit Imaging. 2005;18(3):234-41. DOI: 10.1007/s10278-005-5150-4 PMID: 15924275.

10. Farneti D, Turroni V, Genovese E. Aspiration: diagnostic contributions from bedside swallowing evaluation and endoscopy. Acta Otorhinolaryngol Ital. 2018;38(6):511-6. DOI: $10.14639 / 0392-100 X-1967$ PMID: 30623896.

11. Trapl M, Enderle P, Nowotny M, Teuschl Y, Matz K, Dachenhausen A, et al. Dysphagia bedside screening for acute-stroke patients: the Gugging Swallowing Screen. Stroke. 2007;38(11):2948-52. DOI: 10.1161/STROKEAHA.107.483933 PMID: 17885261.

12. Takahashi Y, Minamikawa T, Yonezawa N, Komatsu H, Nibu K, Komori T. Analysis of the hyoid motion of tongue cancer patients. J Oral Maxillofac Surg Med Pathol. 2017;29(2):105-9. DOI: 10.1016/j.ajoms.2016.09.007.

13. Jeong WH, Lee WJ, Roh TS, Lew DH, Yun IS. Long-term functional outcomes after total tongue reconstruction: Consideration of flap types, volume, and functional results. Microsurgery. 2017;37(3):190-6. DOI: 10.1002/micr.22440 PMID: 26118978.

14. Bova R, Cheung I, Coman W. Total glossectomy: is it justified? ANZ J Surg. 2004;74(3):134-8. DOI: 10.1046/j.14452197.2004.02912.x PMID: 14996160.

15. Dziegielewski PT, Ho ML, Rieger J, Singh P, Langille M, Harris JR, et al. Total glossectomy with laryngeal preservation and free flap reconstruction: objective functional outcomes and systematic review of the literature. Laryngoscope. 2013;123(1):140-5. DOI: 10.1002/lary.23505 PMID: 22952109.

16. Rigby $\mathrm{MH}$, Hayden RE. Total glossectomy without laryngectomy - a review of functional outcomes and reconstructive principles. Curr Opin Otolaryngol Head Neck Surg. 2014;22(5):414-8. DOI: $10.1097 /$ MOO.0000000000000076 PMID: 25003844.

17. Tiwari R, Karim AB, Greven AJ, Snow GB. Total glossectomy with laryngeal preservation. Arch Otolaryngol Head Neck Surg. 1993;119(9):945-9. DOI: 10.1001/archotol.1993.01880210033005 PMID: 8357594.

18. Thankappan K, Iyer S, Menon JR. Dysphagia Management in Head and Neck Cancers. 1 ed. Singapore: Springer; 2018. XXII, 404 p. DOI: 10.1007/978-981-10-8282-5.

19. Hagner M, Frey DL, Guerra M, Dittrich AS, Halls VS, Wege $\mathrm{S}$, et al. New method for rapid and dynamic quantification of elastase activity on sputum neutrophils from patients with cystic fibrosis using flow cytometry. Eur Respir J. 2020;55(4). DOI: 10.1183/13993003.02355-2019 PMID: 32139467. 